\title{
The role of nebulised budesonide in the treatment of exacerbations of COPD
}

\author{
H. Gunen, S.S. Hacievliyagil, O. Yetkin, G. Gulbas, L.C. Mutlu and E. In
}

ABSTRACT: The present study was designed to evaluate the hypothesis that nebulised budesonide (NB) might be an alternative to systemic corticosteroids (SC) in the treatment of patients with exacerbations of chronic obstructive pulmonary disease (ECOPD).

Patients hospitalised with ECOPD $(n=159)$ were randomised into three groups. Group 1 received only standard bronchodilator treatment (SBDT), group 2 received SC (40 mg prednisolone) plus SBDT, and group 3 received NB $(1,500 \mu$ q.i.d.) plus SBDT. Improvement during 10-day hospitalisation was compared with exacerbation and rehospitalisation rates after discharge.

While mean $\pm S D$ age was $64.1 \pm 8.9$ yrs (female/male $=0.1$ ), mean forced expiratory volume in one second (FEV 1 ) at admission was found to be $37.2 \pm 12.2 \%$ predicted. Arterial blood gases and spirograms recovered faster in groups 2 and 3. While improvements in arterial oxygen tension $\left(\mathrm{Pa}_{\mathrm{a}} \mathrm{O}_{2}\right)$ and forced vital capacity (FVC) in group 2 , and improvements in $\mathrm{Pa}_{2} \mathrm{O}_{2}, \mathrm{FVC}$ and $\mathrm{FEV} \mathrm{V}_{1}$ in group 3, became significant at 24-h control, the first significant improvement in group 1 appeared in arterial oxygen saturation at 72-h control. The mean improvement of $\mathrm{Pa}_{\mathrm{a}} \mathrm{O}_{2}$ after 10 days was 1.20 and $1.06 \mathrm{kPa}(9$ and $8 \mathrm{mmHg}$ ) higher in group 2 and 3, respectively, than in group 1. Blood glucose exhibited an upward trend only in group 2.

The study demonstrates that nebulised budesonide may be an effective and safe alternative to systemic corticosteroids in the treatment of exacerbations of chronic obstructive pulmonary disease.

KEYWORDS: Chronic obstructive pulmonary disease, exacerbation, nebulised budesonide, systemic corticosteroid

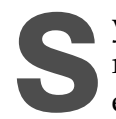
ystemic corticosteroids are strongly recommended in the management of exacerbations of chronic obstructive pulmonary disease (ECOPD) by all international guidelines [1, 2]. Despite their proven efficacy, there are still some drawbacks with respect to their acute and chronic adverse effects. Considering that COPD patients are elderly and relatively immobilised, development of adverse effects due to systemic corticosteroid use is a major concern. In the development of adverse effects like osteoporosis and bone fractures, thinning of the skin, posterior subcapsular cataract formation, glucose intolerance and myopathy, the cumulative received dose of systemic corticosteroid is the most important parameter [3-6]. It is well known that exacerbation rate is significantly higher in some COPD patients, and that these patients need larger amounts of systemic corticosteroids for the control of exacerbations in a certain period of time [7, 8]. Hence, the risk of development of severe adverse effects due to repeated courses of systemic corticosteroid is much higher in this subgroup, and this condition leads clinicians to seek alternative options.

Nebulised corticosteroids have been available for the last decade. Since their topical anti-inflammatory activity is high, they are safely used as a substitute for inhaled corticosteroids in patients with stable COPD and bronchial asthma, where necessary. However, there are only a few studies in the literature related to their use in the management of exacerbations of bronchial asthma and COPD [9-14]. The total daily dosages used in the relevant studies ranged $1-8 \mathrm{mg}$, differing according to the methodology and the patient groups used in the studies. Preliminary data suggest that nebulised corticosteroids have a similar efficacy to systemic corticosteroids in the treatment of exacerbations of bronchial asthma and COPD.

Although the available data about the use of nebulised corticosteroids in ECOPD indicate a positive impact, this has yet to be explored in
AFFILIATIONS

Dept of Pulmonary Medicine, Turgut Ozal Research Centre, Inonu University, Malatya, Turkey.

CORRESPONDENCE

H. Gunen

Dept of Pulmonary Medicine Turgut Ozal Research Centre Inonu University

Malatya 44069

Turkey

Fax: 904223410728

E-mail: hgunen@yahoo.com

Received:

June 052006

Accepted after revision:

January 082007

STATEMENT OF INTEREST

None declared. 
further studies. Accordingly, the current authors designed a study to evaluate the safety and efficacy of nebulised budesonide suspension compared with systemic corticosteroid in the treatment of patients with ECOPD requiring hospitalisation.

\section{PATIENTS AND METHODS}

The study was conducted at Turgut Ozal Research Centre of Inonu University (Malatya, Turkey). The study protocol was approved by the ethics committee of the centre. COPD patients who were hospitalised for an exacerbation were prospectively enrolled in the study. Informed consent was obtained from all the participants. The patients' diagnosis of COPD was made according to the criteria set by the American Thoracic Society [15]. An exacerbation was defined as the presence of worsening in at least two of the following symptoms: cough, purulent sputum and dyspnoea. The patients were hospitalised in cases when one or more of the following indications existed: severely increased symptoms; new onset of cyanosis and peripheral oedema; confusion; lethargy; coma; use of accessory muscles for ventilation; significant comorbidities; failure to respond to initial treatment; the judgement that treatment at home is insufficient; acidosis; persistent or worsening hypoxaemia and/or severe or worsening hypercapnia; and new onset arrhythmias. COPD patients hospitalised for specific reasons, e.g. pneumonia, pulmonary emboli, congestive heart failure and pneumothorax etc., as the cause of exacerbation were excluded. Only patients with level II exacerbation were included in the study, and patients with a risk of imminent respiratory failure requiring mechanical ventilation or direct admission to the intensive care unit (ICU) (level III exacerbation) were excluded [2]. Patients who had utilised systemic corticosteroids or had an exacerbation in the preceding month were not enrolled. The patients were registered in the study only once at the index hospitalisation. The ClinicalTrials.gov identifier of the study is NCT00274222.

\section{Treatments during hospitalisation}

The participants received apparently identical treatment. To achieve administration of identical treatment arms, the patients were given same number of scheduled nebulised solutions every day (eight times a day) and were infused with a single physiological saline solution $(50 \mathrm{~mL})$ intravenously in the morning. The patients utilising systemic corticosteroid received it in this solution, and addition of systemic corticosteroid did not have any effect on appearance of the solution. All nebulised solutions were delivered using the same type of nebuliser (Medel Aerofamily Jet Nebulizer; S. Polo di Torrile, Parma, Italy). The medications were prepared outside the patients' rooms by a nurse, and the patients were not informed which medications were delivered (or not) in nebulised forms and in i.v. solutions.

The patients were randomly sorted into three groups. The treatment groups were as follows. Group 1 received bronchodilator treatment with nebulised salbutamol (2.5 $\mathrm{mg}$ q.i.d.; Ventolin nebules, $2.5 \mathrm{mg} / 2.5 \mathrm{~mL}$ salbutamol; GlaxoSmithKline, Istanbul, Turkey) and nebulised ipratropium bromide $(0.5 \mathrm{mg}$ q.i.d.; Atrovent flakon, $0.5 \mathrm{mg} / 2 \mathrm{~mL}$ ipratropium bromide; Boehringer Ingelheim, Istanbul, Turkey) in separate sessions. Their mini i.v. solution was infused as empty.
Group 2 received the same bronchodilator treatments as group 1. Their mini i.v. solution included $40 \mathrm{mg}$ prednisolone (Prednol-L ampul, $40 \mathrm{mg}$ prednisolone; Mustafa Nevzat, Istanbul, Turkey).

Group 3 received a combined nebulised solution of salbutamol and ipratropium bromide q.i.d. (Combivent flakon, ipratropium bromide $0.5 \mathrm{mg}$ and salbutamol $2.5 \mathrm{mg} / 2.5 \mathrm{~mL}$; Boehringer Ingelheim). This group of patients also utilised nebulised budesonide $(1,500 \mu \mathrm{g}$ q.i.d.; Pulmicort nebuliser, $0.5 \mathrm{mg} / 2 \mathrm{~mL}$ budesonide; AstraZeneca, Istanbul, Turkey). The combined form of nebulised bronchodilator includes the same doses of salbutamol and ipratropium bromide as in group 1 and 2 . This group received their infusion of mini i.v. solution as empty.

According to the study protocol, the patients could also utilise nebulised salbutamol as rescue medication. All patients were given supplemental oxygen and systemic methylxanthines, and antibiotics were used where signs of bacterial infection existed.

\section{Treatments after discharge}

The patients were hospitalised for $\geqslant 10$ days, and received the treatment strictly as described above. After discharge, all patients were prescribed in a standard fashion with a combined form of inhaled ipratropium bromide plus salbutamol (two puffs q.i.d.; Combivent aerosol, $20 \mu \mathrm{g}$ ipratropium bromide plus $100 \mu \mathrm{g}$ salbutamol in each puff; Boehringer Ingelheim) and methylxanthines during a 1-month follow-up period. As rescue medication, patients were allowed to use inhaled salbutamol (Ventolin Inhaler, $100 \mu \mathrm{g}$ salbutamol in each puff; GlaxoSmithKline) outside the hospital. If discharged after 11-15 days, the patients in groups 2 and 3 completed the 15-day utilisation of systemic or nebulised corticorticosteroids outside the hospital by using $32 \mathrm{mg}$ of methylprednisolone tablets in the morning (Prednol tablet, 16 mg methylprednisolone in each tablet; Mustafa Nevzat) or inhaled budesonide 1,500 $\mu$ g q.i.d. (Pulmicort turbuhaler, $100 \mu \mathrm{g}$ budesonide per dose; AstraZeneca), respectively. Until patients had been hospitalised for 15 days, the initial treatment was not changed. If the hospitalisation period exceeded 15 days, both forms of corticosteroid preparations and infusion of physiological saline solutions were discontinued.

\section{Data collection}

Complete blood counts, detailed biochemical analysis, spirometric measurements and arterial blood gas analysis were carried out at admission, $24 \mathrm{~h}, 72 \mathrm{~h}, 7$ days and 10 days. In addition, the following were recorded: adverse effects developed; COPD deterioration; admission to the ICU; respiratory failure; patient's withdrawal for any reason; delayed discharge (beyond 15 days); in-hospital deaths; deaths after discharge within 1 month; exacerbation; and rehospitalisation rates within 1 month after discharge. Exacerbation after discharge was defined by an unscheduled visit to any medical unit due to increase in COPD symptoms, e.g. breathlessness, sputum production or cough. Patients' status after discharge was assessed by phone calls and home visits every week during a 1-month period after discharge. Comorbidity was measured for all patients according to the model developed by CHARLSON et al. [16]. This index gives different scores for different chronic 
illnesses, in order to predict mortality. In this method, severe diseases are assigned higher scores, and milder diseases are given lower scores (congestive heart failure: 1, malignancy: 2, severe liver disease: 3, AIDS: 6, etc.).

\section{Measurements}

Spirometric examination at admission was carried out using a Vmax 20c spirometer (SensorMedics Corp., Yorba-Linda, CA, USA). This test was performed in a standard fashion. The spirograms having the largest forced expiratory volume in one second (FEV1) and forced vital capacity (FVC), selected among at least two technically acceptable spirometric measurements, were used in the analysis. Patients who missed more than one spirometric examination were excluded from the study. Arterial blood gas analysis was performed while breathing room air at rest.

\section{Statistical analysis}

Including the patients who might drop out from the study during the hospitalisation period, a minimum sample size of 50 was required in order to obtain power reaching an acceptable level ( $80 \%$ power, $\alpha=0.05$ ). It was anticipated that the dropout rate might be $\sim 20 \%$ with this protocol. For comparison of changes in continuous variables between and within the groups, ANOVA and paired t-tests were used, respectively. The Chi-squared method was used to compare the number of patients in each group with regard to the parameters related to the clinical indicators of treatment success, which included: admission to the ICU; death; adverse events; withdrawal of consent; deterioration of COPD; exacerbation rates; and hospitalisation rates after discharge. A twosided $\mathrm{p}$-value $<0.05$ was considered to be statistically significant.

\section{RESULTS}

In total, 53 patients were enrolled in each group. Data from 38 patients were not evaluated due to exclusion during the hospitalisation period of the study; 121 patients completed the study (39 in group 1, 40 in group 2, 42 in group 3). The main reasons for exclusion were: the inability to perform two consecutive spirometric examinations $(n=10)$; noncompliance with the treatment $(n=8)$; adverse effects $(n=6)$; treatment failure or admission to the ICU $(n=5)$; withdrawal of consent $(n=5)$; and request for early discharge $(n=4)$. The rates of dropouts were similar in all three groups (26\% in group $1,24 \%$ in group 2, 21\% in group 3). Further analysis of the groups according to the reasons of exclusion also revealed a similar distribution in each group. Antibiotics were prescribed for 59, 63 and $57 \%$ of the patients in groups 1, 2 and 3, respectively $(\mathrm{p}=0.882)$. General characteristics of the patients at admission who completed the study are presented in table 1 . There was no significant difference between the groups. Another 11 patients were lost to follow-up during a 1-month period after discharge (four, three and four patients in groups 1, 2 and 3, respectively), and one patient from each of groups 1 and 2 died during this period.

Arterial blood gas analysis was performed in all patients, but initial spirograms could not be obtained in 20 patients: in 11 due to lack of patient cooperation, and in nine due to technical problems. Although initial spirometric and arterial blood gas parameters were similar between the groups, absolute values

\begin{tabular}{|c|c|c|c|}
\hline \multirow[t]{2}{*}{ TABLE 1} & \multirow[b]{2}{*}{ Group $1^{\#}$} & \multirow{2}{*}{\multicolumn{2}{|c|}{ Group $3^{+}$}} \\
\hline & & & \\
\hline Subjects $n$ & 39 & 40 & 42 \\
\hline Age yrs & $63.5 \pm 10.1$ & $64.9 \pm 7.1$ & $63.9 \pm 9.7$ \\
\hline Sex M/F & $35 / 4$ & $33 / 7$ & $35 / 7$ \\
\hline Disease duration yrs & $11.1 \pm 8.5$ & $10.8 \pm 5.6$ & $10.8 \pm 6.6$ \\
\hline Smoking load pack-yrs & $44.7 \pm 19.5$ & $43.4 \pm 21.4$ & $46.9 \pm 21.7$ \\
\hline Current smokers \% & 44 & 45 & 50 \\
\hline Haematocrit \% & $49.0 \pm 6.1$ & $48.9 \pm 5.8$ & $48.2 \pm 6.5$ \\
\hline $\begin{array}{l}\text { Leukocyte count } \\
10^{9} \cdot \mathrm{L}^{-1}\end{array}$ & $13355 \pm 5546$ & $12715 \pm 5145$ & $13605 \pm 5373$ \\
\hline BUN $\mathbf{m g} \cdot \mathrm{dL}^{-1}$ & $21.9 \pm 9.4$ & $24.9 \pm 13.1$ & $20.9 \pm 8.8$ \\
\hline Glucose $\mathbf{m g} \cdot \mathrm{dL}^{-1}$ & $114.0 \pm 31.7$ & $116.4 \pm 37.8$ & $114.3 \pm 24.9$ \\
\hline FVC \% pred & $64.5 \pm 21.5$ & $57.5 \pm 17.7$ & $64.3 \pm 20.4$ \\
\hline FEV $1 \%$ pred & $36.7 \pm 11.9$ & $35.3 \pm 11.7$ & $39.6 \pm 12.9$ \\
\hline $\mathrm{FEV}_{1 / \mathrm{FVC}}$ & $46.8 \pm 15.9$ & $48.4 \pm 13.4$ & $48.4 \pm 13.2$ \\
\hline FEF $25-75 \% \%$ pred & $16.4 \pm 7.8$ & $15.7 \pm 8.4$ & $20.6 \pm 16.1$ \\
\hline pH & $7.41 \pm 0.09$ & $7.41 \pm 0.08$ & $7.41 \pm 0.09$ \\
\hline $\mathrm{Sa}, \mathrm{O}_{2} \%$ & $83.6 \pm 10.0$ & $80.1 \pm 12.4$ & $79.9 \pm 13.7$ \\
\hline $\mathrm{Pa}, \mathrm{O}_{2} \mathrm{mmHg}$ & $52.4 \pm 11.1$ & $49.1 \pm 12.6$ & $50.1 \pm 14.8$ \\
\hline $\mathrm{Pa}, \mathrm{CO}_{2} \mathrm{mmHg}$ & $47.4 \pm 16.7$ & $51.4 \pm 10.3$ & $46.8 \pm 12.7$ \\
\hline Comorbidity index & $1.55 \pm 0.8$ & $1.53 \pm 0.7$ & $1.56 \pm 0.8$ \\
\hline
\end{tabular}

Data are presented as mean $\pm \mathrm{SD}$, unless otherwise indicated. $\mathrm{M}$ : male; $\mathrm{F}$ : female; BUN: blood urea nitrogen; FVC: forced vital capacity; \% pred: \% predicted; FEV1: forced expiratory volume in one second; FEF25-75\%: mean forced expiratory flow between 25 and $75 \%$ of $\mathrm{FVC} ; \mathrm{Sa}_{3} \mathrm{O}_{2}$ : arterial oxygen saturation; $\mathrm{Pa}, \mathrm{O}_{2}$ : arterial oxygen tension; $\mathrm{Pa}_{\mathrm{a}} \mathrm{CO}_{2}$ : arterial carbon dioxide tension. \#: Only bronchodilator; ${ }^{\natural}$ : systemic corticosteroid; ${ }^{+}$: nebulised budesonide. $1 \mathrm{mmHg}=0.133 \mathrm{kPa}$.

after 10 days were better in groups 2 and 3 than in group 1 . With regard to the absolute values of arterial blood gases and spirometric measurements at 10 days, mean forced expiratory flow between 25 and 75\% of FVC (FEF25-75\%) value in group 3 was significantly higher than the values in group 1 and 2 $(p=0.03$ and $p=0.027$ respectively). In addition to this, while direct comparison of arterial blood gases and spirometric parameters did not reveal any difference between group 1 and 2, FEV1 was also found to be significantly higher in group 3 than in group $1 \quad(p=0.004)$. When comparison was made between groups 1 and 3 for absolute mean values of FVC and FEV1/FVC, the trend was very close to the threshold value in favour of group 3 ( $p=0.081$ and $p=0.077$, respectively). In the same manner, comparisons made for FEV1 also revealed a similar trend between groups 2 and 3 , in favour of group 3 $(\mathrm{p}=0.057)$.

In order to better assess the response to treatment, the improvement rates (difference between admission values and 10-day values) were also compared between different treatment arms. Among the parameters evaluated, improvement rates in arterial oxygen saturation $\left(\mathrm{Sa}_{\mathrm{a}} \mathrm{O}_{2}\right)$ arterial oxygen tension $\left(\mathrm{Pa}_{1} \mathrm{O}_{2}\right), \mathrm{FEV} 1$ and FVC were significantly higher in group 2 and 3 than in group 1 . Mean improvements in $\mathrm{Pa}_{1} \mathrm{O}_{2}$ at 10 days (final complete evaluation time) were 1.20 and 
TABLE 2 Patient characteristics at different follow-up times after hospitalisation

\begin{tabular}{|c|c|c|c|c|c|c|}
\hline Characteristics & Group ${ }^{\#}$ & Baseline & At $24 \mathrm{~h}$ & At $72 \mathrm{~h}$ & At 7 days & At 10 days \\
\hline \multirow[t]{2}{*}{ FVC \% pred } & 1 & $64.5 \pm 21.5$ & $64.7 \pm 20.8$ & $66.1 \pm 22.9$ & $66.6 \pm 20$ & $70.1 \pm 22.3$ \\
\hline & 3 & $64.3 \pm 20.4$ & $68.7 \pm 21.6$ & $70.0 \pm 19.7$ & $75.5 \pm 23.9$ & $78.8 \pm 21.8$ \\
\hline \multirow[t]{2}{*}{ FEV $1 \%$ pred } & 1 & $36.7 \pm 11.9$ & $36.5 \pm 11.2$ & $37.1 \pm 13.4$ & $38.6 \pm 14.9$ & $40.7 \pm 15.0$ \\
\hline & 2 & $35.3 \pm 11.7$ & $36.4 \pm 12.8$ & $38.4 \pm 15.3$ & $42.9 \pm 13.9$ & $44.2 \pm 14.6$ \\
\hline \multirow{2}{*}{ FEV1/FVC } & 2 & $48.4 \pm 13.4$ & $47.5 \pm 12.1$ & $48.4 \pm 13.7$ & $48.1 \pm 11.9$ & $47.5 \pm 11.7$ \\
\hline & 3 & $48.4 \pm 13.2$ & $48.2 \pm 14.1$ & $49.1 \pm 12.6$ & $50.3 \pm 13.0$ & $51.1 \pm 14.0$ \\
\hline \multirow[t]{3}{*}{ FEF $25-75 \% \%$ pred } & 1 & $16.4 \pm 7.8$ & $15.8 \pm 8.7$ & $16.6 \pm 7.4$ & $17.0 \pm 8.9$ & $17.7 \pm 9.1$ \\
\hline & 2 & $15.7 \pm 8.4$ & $15.9 \pm 9.3$ & $16.4 \pm 10.4$ & $16.6 \pm 9.9$ & $17.4 \pm 10.0$ \\
\hline & 3 & $20.6 \pm 16.1$ & $21.1 \pm 15.8$ & $20.7 \pm 16.1$ & $21.6 \pm 12.0$ & $22.9 \pm 11.7$ \\
\hline $\mathrm{Pa}, \mathrm{O}_{2} \mathrm{mmHg}$ & 1 & $53.4 \pm 11.1$ & $54.4 \pm 10.9$ & $55.7 \pm 12.3$ & $56.1 \pm 12.7$ & $57.5 \pm 11.4$ \\
\hline \multirow{2}{*}{$\mathrm{Pa}, \mathrm{CO}_{2} \mathrm{mmHg}$} & 2 & $51.4 \pm 10.3$ & $50.9 \pm 11.3$ & $48.1 \pm 9.7$ & $45.9 \pm 10.0$ & $45.2 \pm 9.8$ \\
\hline & 3 & $46.8 \pm 12.7$ & $47.8 \pm 9.8$ & $46.2 \pm 10.2$ & $45.1 \pm 10.7$ & $44.5 \pm 10.5$ \\
\hline \multirow[t]{3}{*}{$\mathrm{Sa}, \mathrm{O}_{2} \%$} & 1 & $83.6 \pm 10.0$ & $84.7 \pm 9.1$ & $86.1 \pm 8.2$ & $88.2 \pm 7.2$ & $88.7 \pm 6.4$ \\
\hline & 2 & $80.1 \pm 12.4$ & $82.2 \pm 10.1$ & $85.4 \pm 9.7$ & $88.9 \pm 7.1$ & $90.5 \pm 6.8$ \\
\hline & 3 & $79.9 \pm 13.7$ & $81.9 \pm 11.7$ & $85.8 \pm 8.8$ & $89.7 \pm 6.3$ & $90.9 \pm 5.3$ \\
\hline \multirow[t]{3}{*}{ Glucose $\mathbf{m g} \cdot \mathrm{dL}^{-1}$} & 1 & $114.0 \pm 31.7$ & $110.0 \pm 33.5$ & $106.6 \pm 25.5$ & $104.5 \pm 18.9$ & $102.8 \pm 16.4$ \\
\hline & 2 & $126.4 \pm 37.8$ & $114.9 \pm 35.1$ & $112.3 \pm 29.8$ & $127.1 \pm 27.7$ & $129.1 \pm 23.4$ \\
\hline & 3 & $114.3 \pm 24.9$ & $113.7 \pm 27.9$ & $110.4 \pm 31.1$ & $107.1 \pm 25.5$ & $104.6 \pm 22.7$ \\
\hline
\end{tabular}

Data are presented as mean \pm SD. FVC: forced vital capacity; \% pred: \% predicted; FEV1: forced expiratory volume in one second; FEF25-75\%: mean forced expiratory flow between 25 and $75 \%$ of $\mathrm{FVC} ; \mathrm{Pa}_{1} \mathrm{O}_{2}$ : arterial oxygen tension; $\mathrm{Pa}_{1} \mathrm{CO}_{2}$ : arterial carbon dioxide tension; $\mathrm{Sa}, \mathrm{O}_{2}$ : arterial oxygen saturation. ${ }^{*}$ : Group 1 received only bronchodilator treatment, group 2 received systemic corticosteroid in addition to bronchodilator treatment and group 3 received high-dose nebulised budesonide in addition to bronchodilator treatment. $1 \mathrm{mmHg}=0.133 \mathrm{kPa}$.

$1.06 \mathrm{kPa}(9$ and $8 \mathrm{mmHg})$ higher in group $2(\mathrm{p}=0.000)$ and 3 $(p=0.009)$, respectively, than in group 1 (table 2$)$. Similarly, higher improvement rates of $5.3 \%(p=0.022)$ and $5.9 \%$ $(\mathrm{p}=0.011)$ in $\mathrm{S}_{2} \mathrm{O}_{2}$, of $10.6 \%(\mathrm{p}=0.006)$ and $8.9 \%(\mathrm{p}=0.007)$ in FVC, and of $4.9 \%(p=0.038)$ and $7.2 \%(p=0.001)$ in FEV1 were recorded in group 2 and 3 , respectively (table 2 ). The differences between groups 2 and 3 were not statistically significant, except for the comparison of improvement rates in arterial carbon dioxide tension $\left(\mathrm{Pa}_{1} \mathrm{CO}_{2} ; \mathrm{p}=0.046\right)$. Mean improvement in $\mathrm{Pa}_{1} \mathrm{CO}_{2}$ was found to be $0.52 \mathrm{kPa}(3.9 \mathrm{mmHg})$ higher in group 2 than in group 3.

In the $24 \mathrm{~h}, 72 \mathrm{~h}$ and 7 days intermediary periods, patients in groups 2 and 3 showed better recovery. Improvement rates in spirometric and arterial blood gas parameters at these periods are shown in table 2 and in figures 1 and 2. When compared to the initial values, the first statistically significant improvement in group 1 appeared in $\mathrm{Sa}_{2} \mathrm{O}_{2}$ at 72 -h control $(\mathrm{p}=0.041)$. However, at 24-h control, improvements in $\mathrm{Pa}_{\mathrm{a}} \mathrm{O}_{2} \quad(\mathrm{p}=0.038)$ and FVC $(\mathrm{p}=0.032)$ became statistically significant in group 2 , and improvements in $\mathrm{Pa}_{\mathrm{a}} \mathrm{O}_{2}(\mathrm{p}=0.03), \mathrm{FVC}(\mathrm{p}=0.024)$ and FEV1 $(\mathrm{p}=0.014)$ became statistically significant in group 3 (table 2$)$. At the 7-day control, while all improvement rates in groups 2 and 3 with regard to the spirometric (except FEF25-75\% and FEV1/FVC) and arterial blood gas parameters (except $\mathrm{pH}$ ), reached a statistically significant level, improvements in FVC and $\mathrm{Pa}_{1} \mathrm{O}_{2}$ in addition to $\mathrm{FEF} 25-75 \%$ and $\mathrm{FEV} 1 / \mathrm{FVC}$ were not yet statistically significant in group 1 (table 2). Comparisons between or within groups for improvement rates in FEF25$75 \%$ did not yield any statistically significant result at any period. Later on, improvement rate in FEV1/FVC became statistically significant at 10-day control only in group 3 $(\mathrm{p}=0.019)$.

Detailed differential count of blood cells and measurements for biochemical parameters were carried out at the same periods as the spirometric and arterial blood gas analyses. Except in blood glucose levels, there was no significant difference between the groups with respect to the haematological and biochemical parameters at admission, $24 \mathrm{~h}, 72 \mathrm{~h}, 7$ days and 10 days (table 2). Absolute blood glucose level was found to be significantly higher in group 2 than the glucose level in other groups in 7 - and 10 -day measurements $(p<0.05)$. In addition to this, while mean blood glucose levels were decreasing during the hospitalisation period in groups 1 and 3, it was found to be higher than the admission value in group 2 at 7 - and 10-day controls (fig. 3).

An important primary end-point in evaluating the efficacy of nebulised corticosteroids in the present study was the number of patients with early and delayed discharge in the groups. As mentioned earlier, patients completed their 10-day controls at 
the hospital. Thus, the fraction of patients discharged on day 10 became 54, 50 and $45 \%$ in group 1, 2 and 3, respectively (table 3). The delayed discharge (beyond 15 days) occurred in 10,10 and $7 \%$ in the relevant groups, respectively (table 3 ). Proportions of the patients with early (relatively) and delayed discharge did not yield any statistically significant results between the groups.

Another primary end-point was the attack rates and rehospitalisation rates within 1 month of discharge. Total numbers of exacerbations in groups 1, 2 and 3 were 14, eight and nine, respectively. These exacerbations resulted in hospitalisation eight, four and five times, respectively, during the first month after discharge. Although there was an obvious trend towards the statistically significant site in favour of corticosteroid groups for both analyses, the results did not yield a statistically significant difference between the treatment arms.

\section{DISCUSSION}

In the current study, the short- and long-term efficacy and short-term safety of nebulised budesonide in the treatment were evaluated in patients hospitalised with ECOPD. In the acute phase of the treatment, the recovery rates with regard to spirometric and arterial blood gas parameters did not differ between the groups utilising systemic and nebulised forms of corticosteroids, although the recovery rates were significantly better in the corticosteroid groups than in the group receiving only bronchodilator treatment. In addition to these, blood glucose level showed a significant upward trend in patients treated with systemic corticosteroids.

Systemic corticosteroids are known to effectively improve the clinical parameters in ECOPD when compared with placebo [17-19]. However, these effects are especially significant in the short term, but are less obvious during follow-up [13]. In the present study, it was demonstrated that high-dose nebulised budesonide may replace systemic corticosteroid administration during hospitalisation in patients with ECOPD, except in very severe cases. All spirometric and arterial blood gas parameters improved at a similar rate in both the corticosteroid

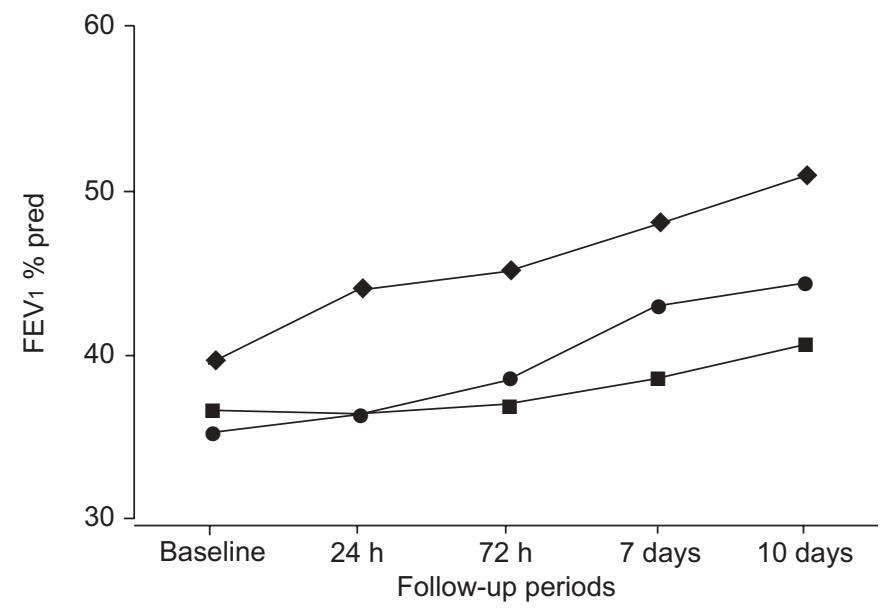

FIGURE 1. Time-course of forced expiratory volume in one second (FEV1) \% predicted for the three different groups after hospitalisation. $\mathbf{\square}$ : Group 1; $\bullet$ : group 2; $\bullet$ group 3 . arms, and recovery of the patients on corticosteroids was better than that of those not receiving any corticosteroid. Moreover, analyses for the improvement rates in FEV1 reached a statistically significant level faster in the nebulised budesonide group, and the improvement in FEV1/FVC became statistically significant only in the nebulised budesonide group. In group 2, only the improvement in $\mathrm{Pa}, \mathrm{CO}_{2}$ was shown to be significantly higher than that in group 3 at the end of the 10-day period. However, this condition was probably due to almost significantly higher mean admission $\mathrm{Pa}_{1} \mathrm{CO}_{2}$ level in group 2 $(p=0.077)$. Previous studies also reached more or less the same findings. MALTAIS et al. [13] demonstrated that the difference between the FEV1 increases in systemic prednisolone $(30 \mathrm{mg}$ b.i.d.) and nebulised budesonide (2 $\mathrm{mg}$ q.i.d.) groups is only $60 \mathrm{~mL}$ over 3 days $(\mathrm{p}>0.05)$. Similarly, MORICE et al. [12] did not find any difference between the improvement rates of FEV1 in the same groups over 5 days of study; the groups were administered $30 \mathrm{mg}$ oral prednisolone versus $4 \mathrm{mg}$ ( $2 \mathrm{mg}$ b.i.d.) nebulised budesonide per day. Recently, MiRICI et al. [14] published a prospective randomised placebo-controlled study. Differing from the previous studies, the study design included arterial blood gas parameters in addition to spirograms. MIRICI et al. [14] also did not show any significant difference between the improvement rates of the relevant parameters of their groups $30 \mathrm{~min}, 6 \mathrm{~h}, 24 \mathrm{~h}, 48 \mathrm{~h}$ and 10 days after hospitalisation due to ECOPD. An important difference of the present study from those previous is that the very acute influence of corticosteroids on clinical parameters was not evaluated presently. Classically, the appearance of the anti-inflammatory effects of corticosteroids takes around $24 \mathrm{~h}$. Before this time, it is very difficult to attribute the recovery of clinical parameters to corticosteroids. In any case, the differentiation of the effects of rapidly acting bronchodilators from those of corticosteroids (if any) cannot be truly made during the first $24 \mathrm{~h}$. Moreover, previous investigators have also stated that slight differences between the improvement rates in corticosteroid arms during the very acute phase could not be translated into any better final outcome [17, 18]. Due to this, the present study was not designed in such a way that the acute effects of corticosteroids

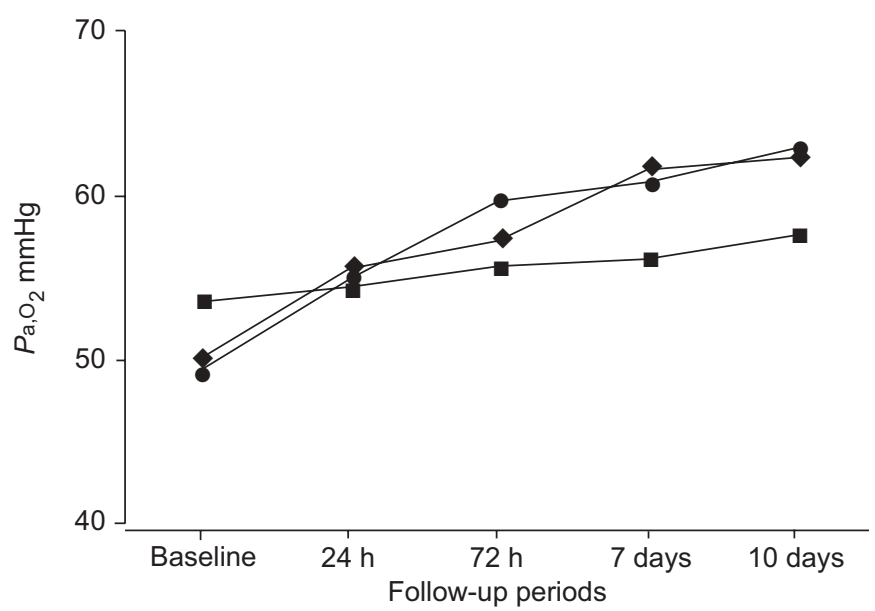

FIGURE 2. Time course of arterial oxygen tension $\left(\mathrm{Pa}_{\mathrm{a}} \mathrm{O}_{2}\right)$ for the three different groups after hospitalisation. $\mathbf{\square}$ : Group 1; $\mathbf{0}$ : group 2; $\bullet$ group 3. $1 \mathrm{mmHg}=0.133 \mathrm{kPa}$. 


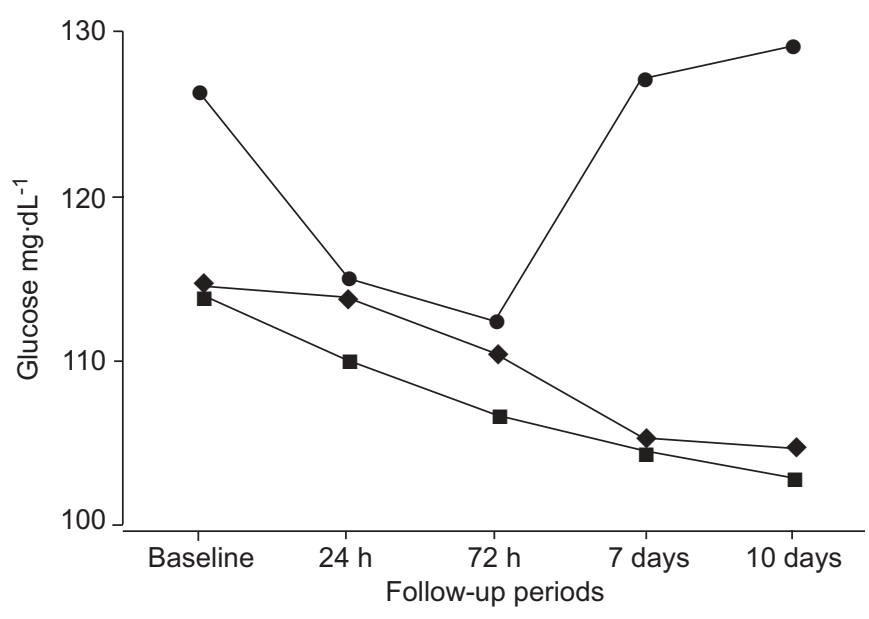

FIGURE 3. Time course of blood glucose levels for the three different groups after hospitalisation. $\mathbf{\square}$ : Group 1; $\bullet$ group 2; : group 3

could be evaluated. For each patient, the dose of nebulised corticosteroid was similar to that used in previous studies. However, it is believed that further studies are needed to assess whether lower doses could achieve equivalent efficacy or if higher doses would be more beneficial.

To the current authors' knowledge, the present study is the first to evaluate the long-term efficacy of nebulised budesonide in these patients. The follow-up period was 1 month after discharge. Criticism for this duration may be received from those claiming that this it could have been longer. However, it would be very difficult to speak about the influence of any type of corticosteroids on the relevant parameters beyond a 1month period [20]. After discharge, exacerbation rates and hospitalisation rates have been the most important tools in the evaluation of long-term efficacy of any drug utilised in ECOPD. Although there is not a perfect method of determining the true exacerbation rates, several investigators are working on it vigorously $[7,8,21,22]$. As has been previously admitted, it is known today that true exacerbation rates are much higher than expected, and the rates yielded by the previous studies far from reflect true exacerbation rates. The main reasons underlying these facts are that COPD patients do not usually seek medical assistance for mild-to-moderate exacerbations and do not report such changes in their condition to the attending physician during follow-up. Thus, whatever precaution was taken, some of the attacks were missed and not recorded. In the present study, the criterion used to assess exacerbation rates was the number of unscheduled visits to any medical unit due to increased symptoms of COPD. Determining the rehospitalisation rates is relatively easy. The methodology of the current authors on this issue may also be criticised, but there is no better or more practical approach. Besides, missing rates for ECOPD in the present study (except for mild attacks) and for rehospitalisation should be probably close to zero, because the patients were questioned once every week during the first month after discharge. Patients on corticosteroids revealed much better exacerbation and rehospitalisation rates, though these were not statistically significant. On the corticosteroid arms, these rates became almost half the rate in the only bronchodilator arm. Due to the limited number of patients in the study groups, the relevant scores did not reach a statistically significant level.

Due to the specific design of the present study, length of hospital stay can not be directly used as a parameter in the comparison of groups. Since patients were kept at the hospital for $\geqslant 10$ days, one can only speak in terms of the patients discharged at the 10th day and about the patients with delayed discharge (after the 15th day). From this specific point of view, no impact of corticosteroids was found on the hospitalisation period, as was the case in previous studies [13, 17, 18].

Adverse effects of the systemic corticosteroids are another important concern during the treatment of ECOPD. Even administration of a single dose of systemic corticosteroids has been shown to increase the fracture risk in elderly patients with chronic lung disease, as is the case in COPD [21]. However, total dose received in a lifetime (cumulative dose) is the most important determinant for the appearance of adverse effects due to utilisation of systemic corticosteroids [6, 13, 23]. As shown earlier, some patients with COPD undergo more frequent exacerbations, thus they receive higher amounts of systemic corticosteroids [7, 8, 20, 22, 24]. Especially in these patients, clinicians hesitate to prescribe systemic corticosteroids for every exacerbation. Since the systemic bioavailability of nebulised corticosteroids is almost negligible, development

TABLE 3 Percentage of the patients discharged at different times after hospitalisation, and exacerbation and hospitalisation rates after discharge
Group $1^{\#}$
Group $2^{\circ}$
Group $3^{+}$

$\begin{array}{lccc}\text { Patients n } & 39 & 40 & 42 \\ \text { Patients discharged at day } \mathbf{1 0} \% & 54 & 50 & 45 \\ \text { Patients discharged after 15 days \% } & 10 & 10 & 7 \\ \begin{array}{l}\text { Exacerbation rates within 1 month of } \\ \quad \text { discharge }\end{array} & 14 & 8 & 9 \\ \begin{array}{l}\text { Rehospitalisation rates within 1 month of } \\ \quad \text { discharge }\end{array} & 8 & 4 & 5\end{array}$

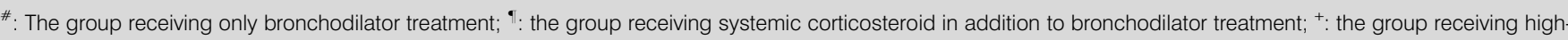
dose nebulised budesonide in addition to bronchodilator treatment. 
of systemic adverse effects are not expected practically. Adverse effects due to the utilisation of nebulised or inhaled corticosteroids are rather limited to their local effects like oropharyngeal candidiasis, hoarseness, etc. From this point of view, frequent use of high-dose nebulised budesonide seems to be virtually safe. However, it should be kept in mind that this issue has not been investigated at all. In the present study too, no adverse effect directly due to its use was reported, nor were there differences between the groups with regard to percentages of patients who were excluded or withdrawn from the study for any reason. To better assess the effects of systemic and nebulised corticosteroids, many haematological and biochemical parameters were determined. Except for blood glucose levels, no differences were found between the groups during the first 10 days after hospitalisation. Initial blood glucose level was similar between the groups, but in the 7- and 10-day controls after hospitalisation it demonstrated an upwards trend in the group receiving systemic corticosteroid. The trend was downwards in the high-dose nebulised budesonide group and the only bronchodilator group (fig. 3).

In the original design of the present study, the evaluation of parameters such as inspiratory capacity and important inflammatory markers in COPD like interleukin-8, tumour necrosis factor- $\alpha$, growth factors, etc. were not included [2528]. It is believed that future studies covering these parameters will enable clinicians to understand the pathological mechanisms involved in COPD and to determine the efficacy of nebulised corticosteroids to a greater degree. Although dyspnoea scales have been utilised in measuring clinical response in some studies concerning exacerbations, these scales (modified Medical Research Council dyspnoea scale, Borg's category scale, visual analogue scale, baseline and transition dyspnoea indices, dyspnoea section of the chronic respiratory disease questionnaire, etc.) have been traditionally utilised in measuring dyspnoea during a stable period, during exercise and during the shifting of treatment regimens. To the current authors' knowledge, there is no standard/validated dyspnoea scale for the measurement of dyspnoea during exacerbations of COPD. The parameters used in the present study are basically objective ones, such as arterial blood gases, spirometric measurements and haematological and biochemical analyses. Thus, the changes in their values during the study period are virtually indicative of treatment response in different treatment arms. On the contrary, dyspnoea measurement is a quite subjective process, and changes in its rates stated by the patients may not be a reliable indicator, particularly during an exacerbation. Therefore, it is not thought that the absence of a dyspnoea index in the present study is a serious limitation and so did not have an important impact on the results. Although the size of the study population is rather large and more homogeneous than previous ones, it is believed that this issue necessitates larger multicentric studies, preferably with the addition of a fourth arm of treatment including patients treated with systemic prednisolone plus high-dose nebulised corticosteroid in order to see the additive effect.

In conclusion, high-dose nebulised budesonide was found to be as effective as systemic corticosteroids in short- and longterm treatment of patients hospitalised with exacerbations of chronic obstructive pulmonary disease, except in very severe cases. In addition to this, nebulised budesonide exerted less systemic activity than systemic corticosteroid administration, as indicated by serial blood glucose measurements. In conclusion, the data suggest that high-dose nebulised budesonide may be an alternative to systemic corticosteroids in the treatment of exacerbations of chronic obstructive pulmonary disease.

\section{REFERENCES}

1 Global Initiative for Obstructive Lung Disease - Updated 2005. Global strategy for the diagnosis, management, and prevention of chronic obstructive pulmonary disease. www.goldcopd.org. Date last accessed: December 2005.

2 Celli BR, MacNee W, ATS/ERS Task Force, Standards for the diagnosis and treatment of patients with COPD: a summary of the ATS/ERS position paper. Eur Respir J 2004; 23: 932-946.

3 Decramer M, Lacquet LM, Fagart R, Rogiers P. Corticosteroids contribute to muscle weakness in chronic airflow obstruction. Am Rev Respir Dis 1994; 150: 11-16.

4 McEvoy CE, Ensrud KE, Bender E, et al. Association between corticosteroid use and vertebral fractures in older men with chronic obstructive pulmonary disease. Am J Respir Crit Care Med 1998; 157: 704-709.

5 Henzen C, Suter A, Lerch E, Urbinelli R, Schorno XH, Briner VA. Suppression and recovery of adrenal response after short-term, high-dose glucocorticoid treatment. Lancet 2000; 355: 542-545.

6 Walsh LJ, Wong CA, Oborne J, et al. Adverse effects of oral corticosteroids in relation to dose in patients with lung disease. Thorax 2001; 56: 279-284.

7 Donaldson GC, Seemungal TAR, Bhowmik A, Wedzicha JA. Relationship between exacerbation frequency and lung function decline in chronic obstructive pulmonary disease. Thorax 2002; 57: 847-852.

8 Donaldson GC, Seemungal TA, Patel IS, et al. Airway and systemic inflammation and decline in lung function in patients with COPD. Chest 2005; 128: 1995-2004.

9 Levy ML, Stevenson C, Maslen T. Comparison of short courses of oral prednisolone and fluticasone propionate in the treatment of adults with acute exacerbations of asthma in primary care. Thorax 1996; 51: 1087-1092.

10 Westbroek J, Saarelainen S, Laher M, O’Brien J, Barnacle H, Efthimiou J. Oral steroid-sparing effect of two doses of nebulized fluticasone and placebo in patients with severe chronic asthma. Respir Med 1999; 93: 689-699.

11 Manjra AI, Price J, Lenney W, Hughes S, Barnacle H. Efficacy of nebulized fluticasone propionate compared with oral prednisolone in children with an acute exacerbation of asthma. Respir Med 2000; 94: 1206-1214.

12 Morice AH, Morris D, Lawson-Matthew P. A comparison of nebulized budesonide with oral prednisolone in the treatment of exacerbations of obstructive pulmonary disease. Clin Pharmacol Ther 1996; 60: 675-678.

13 Maltais F, Ostinelli J, Bourbeau J, et al. Comparison of nebulized budesonide and oral prednisolone with placebo in the treatment of acute exacerbations of chronic obstructive pulmonary disease: a randomized controlled trial. Am J Respir Crit Care Med 2002; 165: 698-703.

14 Mirici A, Meral M, Akgun M. Comparison of the efficacy of nebulised budesonide with parenteral corticosteroids in 
the treatment of acute exacerbations of chronic obstructive pulmonary disease. Clin Drug Invest 2003; 23: 55-62.

15 American Thoracic Society, Standards for the diagnosis and care of patients with chronic obstructive pulmonary disease (COPD) and asthma. Am Rev Respir Dis 1987; 136: 225-244.

16 Charlson ME, Pompei P, Ales KL, MacKenzie CR. A new method of classifying prognostic comorbidity in longitudinal studies: development and validation. J Chronic Dis 1987; 40: 373-383.

17 Niewoehner DE, Erbland ML, Deupree RH, et al. Effect of systemic glucocorticoids on exacerbations of chronic obstructive pulmonary disease. Department of Veterans Affairs Cooperative Study Group. N Engl J Med 1999; 340: 1941-1947.

18 Davies L, Angus RM, Calverley PMA. Oral corticosteroids in patients admitted to hospital with exacerbations of chronic obstructive pulmonary disease: a prospective randomised controlled trial. Lancet 1999; 354: 456-460.

19 Thompson WH, Nielson CP, Carvalho P, Charan NB, Crowley JJ. Controlled trial of oral prednisone in outpatients with acute COPD exacerbation. Am J Respir Crit Care Med 1996; 154: 407-412.

20 Aaron SD, Vandemheen KL, Hebert P, et al. Outpatient oral prednisolone after emergency treatment of chronic obstructive pulmonary disease. New Engl J Med 2003; 348: 2618-2625.

21 Wilkinson TMA, Donaldson GC, Hurst JR, Seemungal TA, Wedzicha JA. Early therapy improves outcomes of exacerbations of chronic obstructive pulmonary disease. Am J Respir Crit Care Med 2004; 169: 1298-1303.

22 Donaldson GC, Wilkinson TMA, Hurst JR, Perera WR, Wedzicha JA. Exacerbations and time spent outdoors in chronic obstructive pulmonary disease. Am J Respir Crit Care Med 2005; 171: 446-452.

23 Walsh LJ, Lewis SA, Wong CA, et al. The impact of oral corticosteroid use on bone mineral density and vertebral fracture. Am J Respir Crit Care Med 2002; 166: 691-695.

24 Donaldson GC, Seemungal TAR, Patel IS, Lloyd-Owen SJ, Wilkinson TM, Wedzicha JA. Longitudinal changes in the nature, severity and frequency of COPD exacerbations. Eur Respir J 2003; 22: 931-936.

25 Parker CM, Voduc N, Aaron SD, Webb KA, O'Donnell DE. Physiological changes during symptom recovery from moderate exacerbations of COPD. Eur Respir J 2005; 26: 420-428.

26 Stevenson NJ, Walker PP, Costello RW, Calverley PM. Lung mechanics and dyspnea during exacerbations of chronic obstructive pulmonary disease. Am J Respir Crit Care Med 2005; 172: 1510-1516.

27 Hacievliyagil SS, Gunen H, Mutlu LC, Karabulut AB, Temel I. Association between cytokines in induced sputum and severity of chronic obstructive pulmonary disease. Respir Med 2006; 100: 846-854.

28 Barnes PJ, Chowdhury B, Kharitonov SA, et al. Pulmonary biomarkers in chronic obstructive pulmonary disease. Am J Respir Crit Care Med 2006; 174: 6-14. 